\title{
The Importance of Philosophy in Educational Administration/Management: The Democratic Model
}

\author{
Samuel Asuquo Ekanem, Ph.D,Llb(Hons),BI \\ Department Of Educational Foundations And Administration \\ Cross River University Of Technology, Calabar- Nigeria \\ Email: Samaekanem @yahoo.co.uk \\ Ekeng Nyong Ekefre, Ph.D \\ Department Of Educational Foundation And Administration \\ Cross River University Of Technology, Calabar-Nigeria \\ Email: boisbarytes @yahoo.com
}

\section{Doi:10.5901/mjss.2014.v5n9p501}

\begin{abstract}
A nation's policy on education is the government's way of attaining that aspect of the national goals which can be achieved through the instrumentality of education. No policy on education, however, can be formulated without the primary identification of the overall philosophy and goals of the nation. The general philosophy of Nigeria is to live in unity and harmony as one indivisible, indissoluble, democratic and sovereign nation founded on the principle of freedom, equality and justice, while promoting inter-African solidarity and world peace through understanding. This aim or goal can be realized through education, but this must be based on a firm philosophic foundation. This paper therefore explores the importance of philosophy for the study and practice of educational administration/management in a democratic society. It advocates that education is a normative enterprise that is, driven by basic social values anchored on certain imperatives of social justice. It is therefore these values and imperatives that principally shape every aspect and dimension of educational theory, policy and practice. Viewed from this standpoint, education needs a normative reference to model and drive the democratic processes of everyday life that can provide liberty and self-actualization. For this to be achieved there is need for careful reflection upon national discourses and activities that involve and concern social values. These imperatives must be modeled into educational purposes and practices. It is argued strongly that philosophy constitutes a potent mode of inquiry and epistemic activity that enriches the capacity for reflection and rational thinking which is vital for democratic development.
\end{abstract}

\section{Introduction}

A great number of people in Nigeria see the purpose of education as the preparation of children to get a job or teach the children the skills they require in life to survive. To some also, the purpose of education involves the teaching of the "3Rs," which are Reading, wRiting and aRithmetic. However, philosophers do not see this as the primary goal of education. This is not also the prime goal of several government functionaries. To several school administrators or even professional educators there are other purposes of education that transcend the 3Rs.

It is the confusion that arises from the effort to formulate the purpose and goal of education that make the issue of philosophy of education a crucial discourse. It makes it possible for a search for the relevance and importance of philosophy as it relates to education. The importance of philosophy of education is that it defines the purpose and focus of an educational institution. It becomes a part of its mission statement that in turn defines what subject are taught, how they are taught, how institution are administered or managed and the values that are derivable from what are taught both implicitly and explicitly through the process of administration.

The purpose of education as viewed by philosophers is basically that it is the reproduction of a culture. This takes diverse forms, because in a conservative state or environment, it just implies the maintenance of the status quo, while in a liberal system it implies the teaching of values and more that are not presently part of the culture but are considered desirable. The general implication here is that the values taught are usually that of those that control the schools, which include the church, communities and the government.

This tends to reflect the truism associated with the old proverb that "the hand that rocks the cradle rules the world". Though we concede to the fact children get most of their values from their parents, which is the hand that rocks the 
cradle, they also get much from their teachers. Teachers, especially in a society such as Nigeria, where much of the child raising responsibility has been handed off to the schools, there are the need for them to do their share of cradle rocking. It is also axiomatic that what the schools teach may either support or undermine what parents teach at home.

So, whether intended or unintended, schools function as a tool for the reproduction of culture. This is so because education plays a critical role in the socialization process of a child. It is from the school they learn not just the obvious tools for life but also the cultural mores, values and social tools that shape life.

It is on the basis of this that the paper seeks to $x$-ray the important role of philosophy in educational administration/management.

\section{Education as a Normative Activity}

Education is a normative activity in several diverse ways. The normative aspect of education can be seen in the complex nature of man, which is the foundation of knowledge, education and civil society (Omoregbe: 150). Also, man's nature as a rational and social being constitutes the foundation of morality. For as Omoregbe (2000) opines:

... man is a moral being by nature, that is, by his nature as a rational and social being, morality, in other words, has its root in the rational and social nature of man. If man were not a rational being or if he were not a social being, there would be no such thing as morality. We see then that these three things namely, civil society, education and morality have the same foundation and that is human nature. There are all centered around human nature and are inseparable from it (150).

From the above, it is clear that education cannot be separated from morality or from society. This is because any education that is devoid of morality is said to be "incomplete and useless". Such education it is argued can be very harmful to the society in which the person lives.

Furthermore, education is a process of socialization through which the child internalizes the basic cultural values, mores and essential tools that will aid the child to survive sustainably in the society. So, if education is to fulfill its purpose of catering for some aspects of human needs in the society, it is imperative that it must be imbued with morality. The necessity and inseparability of morality in education can be seen in Rousseau's responses to whether the arts and the sciences have been beneficial to mankind. Rousseau in his famous essay responded in the negative when he said, "since learned men began to appear among us, good men have disappeared." What Rousseau alluded in his response is the fact that the education of those "learned men" was devoid of morality. As a result of lack of morality in the education of these "learned men" their education was not beneficial to mankind since it could not fulfill the purpose of catering for the needs of human nature (Ekanem, 2013).

Also, education is an intentional activity. The entire process of planning and implementation of education is structured or designed purposefully and it is made to be futuristic. This intentionality and purposefulness made education to be value driven. This explains the fact that educational ends are driven by and expressed what we value as individuals and as a group (society). Human beings are not just products of biological reproduction, but are indeed cultural beings and so clearly involved always effort to reproduce what we believe is most valuable about our way of life. Since it is intentional, purposeful, and value driven, education involves, for the individual, family and the society choices that have to do with pattern of life. From a normative perspective, choice in turn needs both ethical and political justification (James \& Banner, 1997, Dewey; 1916 Freire, 1970). This view is aptly captured by Reardon thus "most...agrees that there is a natural value" (23).

Again, being driven by a social choice of a way of life, and being a basic foundation for the membership and participation in society education therefore is an imperative public good. Since education involves the distribution of a basic public good, it raises the issues of distributive justice. And as Rawl opines, "justice is the first virtue of social institutions, as truth is of system of thought. A theory however elegant and economical must be rejected or revised if it is untrue; likewise law and institutions no matter how efficient and well arranged must be reformed or abolished if they are unjust." (1971:1). So, the fundamental question therefore are; what necessarily constitutes a just distribution of educational resources which is achievable through administration/management? What are the basic elements that define justice?

Justice as an ideal can only be attained through a democratic structure in any society. This is because democratic society that is founded on the right of liberty is deontological. The anchor point of this is derived from the sense that it does not provide any prescription of a particular idea of the good life. This implies that individuals have the right to pursue their own idea or the good life, but this have to be in consonance with the equal right of others. This basic freedom 
inspires, generates, and promotes pluralism, a diversity of perspective, values, cultural ways of life among others. Given the legitimate existence of pluralism, and the fundamental importance of cultural, religious, and other forms of identity to personal well being, a society's response to diversity as found in Nigeria is a question of justice, and so should conform with its imperatives (Snauwaert, 2012 ). From this, the questions that can be raised become; what constitutes just response to diversity? How should public institutions, like schools and educational systems, respond to diversity through their administration/management? How do we balance individual's right to cultural recognition with the need for social unity and individual autonomy? What should constitute the basic principles in the articulation of multiculturalism that can satisfy the twin goals of national unity and cultural recognition?

The response to these critical issues, the educational experience must generate content. The organization of this content in the form of curriculum is made up of what knowledge, skills, dispositions, is said to be most valuable. It is on the basis of this that Freire (1998) opined that the curriculum is also value-driven. So, what knowledge, skills and dispositions are most valuable then in multicultural state like Nigeria? And should these reflect our most fundamental values as a nation?

These questions therefore make the issue of how we teach to be as important and critical as what we teach. In a particular sense, pedagogy flows from the logical structure of the curriculum, so by implication is value-driven. In a different sense, the methodology of teaching constitutes a relationship between teacher and student. This relationship establish power, which the teacher exercises in the form of authority over the student. Viewed from this, there are moral and political dimensions, involved in the administration/management of educational institutions. So, the questions therefore are; should a democratic pedagogy follow directly from the core democratic values? Should the value of self reflection (derivable from the Socratic dictum of the unexamined life is not worth living"), and rational deliberation, which is central to democracy, be achieved in the form of a democratic pedagogy? What should constitute the moral and political right in the relationship between the teacher and students?

The responses to these issues and questions are very important and consequential. They fundamentally influence educational purposes and goals, curriculum, pedagogy, organization and governance. These are normative issues and questions and so establish illustratively the normative nature of education.

\section{Education and Democracy: A Normative Framework}

John Dewey is one of the first major contemporary philosophers to have developed a clear idea of what constructionism consists of. His major concern was on the learner. As a result of this concern he considered two fundamental elements that are vital in strengthening democracy and this include the schools and civil society. To Dewey, it is not just enough to expand the voting rights, it is equally of paramount importance to form and generate public opinion through the process of education. The goal of this is to ensure effective means of communication among the citizenry, experts and politicians. Accordingly, Dewey argued that education and learning are social and interactive processes, and so the school itself is a social institution through which social reform can take place. On the basis of this, Dewey advocate strongly for the importance of education as not only being a place to gain knowledge, but also as a place to learn how to live. In his perspective, the purpose of education should not only be concern with the acquisition of a "pre-determined set of skills, but rather, the realization of one's full potential and the ability to use those skills for the greater good in society" (My English Pages, 2013:1).

Also, Dewey opines that education helps the students to realize their full potential, and see schooling as being instrumental in the creation of social change and reform. This perspective indicates the normative framework of education and democracy. So, how can we then engage these normative and social to educational question?

One particular way is to approach these unreflectively. This is to say that we can just" adopt particular values and imperatives unconsciously, based upon our socialization" (Snauwaert, 2013:76). This can be chosen randomly, and we can then adopt them consciously borne out of fear of those that have power over us, or we can involve in a process of conscious, rational reflection and deliberation (Snauwaert, 2012). This can be seen in the words of Dewey as cited by Tozer (1993), when he says "... schools do follow and reflect social 'order' that exists ... accordingly, the problem is not whether the schools should participate in the production of future society (since they do so in many ways) but whether they should do it blindly and irresponsibly or with maximum possible courageous intelligent and responsibility" (121).

Clearly, educational reflection and deliberation require a normative frame of reference. This is because, human beings give interpretation and understanding of experience, which include values and moral and political principles through frames of reference. The implication of this is that we think, reason, choose and value within the context of framework of discourse and understanding (Lakoff, 2002).

It is an established fact that education is contingent upon the specific social and political organization of the society 
within which it is located or founded. For instance, Aristotle opines that "citizenship and civic education are logical expressions of the constitution (Politeia) of the society". Here, the Politeia is not just the formal juridical structure of the legal system but it also constitutes the basic structure of values that defines the society's view of the world (Karier, 1986).

Democracy, which is comprehended not only as a political system but basically as a way of life is anchored on specific values and principles that historically constitutes the politeia of Nigeria. Nigeria as a country possesses a democratic self-identity, which has been sustained in the last fourteen (14) years. And it has been argued that the worst democratic government is better than the best military dictatorship. So, normatively, democracy can and should be adopted as a frame of reference. The reason for this assertion is premised on the fact that it is the ideal most consistent with human well-being and flourishing (Macpherson, 1973). The alternative to any democratic structure would according to Dahl as cited by Snauwaert (2012) "...entail the adoption of intrinsic superiority/inferiority, from which follow the principle of unequal consideration of the goods and interests of persons as well as the platonic ideal of unequal qualifications to participate based upon superior expertise/knowledge- leading to unequal votes hegemony, and exclusion- would apply".

From the above analysis, it is clear that democracy is an appealing and powerful normative frame of reference. Dewey agrees with this when he argues that, "... unless education has some frame of reference it is bound to be aimless, lacking in unified objective. The necessity for a frame of reference must be admitted. There exists in our country such a frame of reference. It is called democracy" (125). So, at the heart of democracy are such values of moral equality and liberty, which is viewed as an equal right of self-determination. Self- determination demands that there should be careful reflection and rational deliberation that borders on social values and consequently, become the imperative of justice. This captures the view of Gutmann as cited by Snauwaert (2012) when he alludes that democracy as a frame of reference demands "conscious social reproduction". Dewey also as cited by Snauwaert (2012) declares that "Democracy also means voluntary choice, based on an intelligence that is the outcome of free association and communication with others. It means a way of living together in which mutual and free consultation rule instead of force..."

So, from the perspective of education as a normative enterprise and democracy as a normative frame of reference, as those involved with the issue of education, that include parents, teacher, administrators, and policy makers should have the capacity to be involved in critical self-reflection and rational deliberation concerning fundamental social values and the imperatives of justice as they have to do with the purposes, content, methods, evaluation, organization, and governance of education. What can be inferred from this is that philosophy is a vital tool in the administration/management of education at all level.

\section{The Importance of Philosophy of Education}

Education has been viewed broadly as a process through which an individual acquires the several physical and social capabilities required by the society that he/she lives to function. Education ideally, is an ultimate value and as such through the provision of social service, it becomes an agent of change.

From this perspective, education is to the nation what the mind is to the body. It is clear that a mind that is sick will be handicapped to coordinate and direct bodily activities. This provides us the basis to argue that education is the most significant complex of social-control mechanism or tools that promotes national development. As the engine room of national development, it is imperative that education must be established or founded on a good philosophy. This is so because philosophy involves thinking deeply about something. So, thinking here, implies thinking deeply about education. Education can be considered a good education when it is able to in plant in those being educated to think deeply about all that they learn, and be able to explore the big questions, and ensure that all the parts they learn fit perfectly together to offer explanation about the world.

Philosophy inspires reasoning about reason, and it assist to improve one's reasoning as it make it possible to be clear, relevant broad, deep, accurate and consistent. Philosophy involves reasoning about what is right and wrong. It is also about reasoning about what constitute knowledge. It is on the basis of this that logic, ethics, epistemology and aesthetics are fundamental topics of philosophy that should be taught to all students so that they can learn to think deeply, relevantly and consistently. It is only philosophy that can challenge us to think outside the box, which is something most people cannot do without assistance.

It is clear from our analysis so far that the focus of this paper is that philosophy is a mode of inquiry and also a discipline that enriches our capacity for effective reflection and rational discourse. This is what makes it vital for both democracy and administration/management of education in a democratic society such as we have experienced in the last fourteen (14) years in Nigeria (1999-2013). Philosophy plays this fundamental role through the provision of frameworks for the understanding and generation of Ideas, methods of reflection and analysis, and evaluation through exercises that 
aids the cultivation of the capacity of reflection and rational discourse (Snauwaert, 2012:77).

From the Greek city-states, which is the starting point of western philosophy, philosophy inspires the basic question that include, how should we live? What is the good life? Philosophy was seen from the beginning as the pursuit of wisdom, of knowledge of how to live the good life, and how to attain enduring happiness as can be seen in the Socratic and Hedonistic notions or concepts of 'virtue' and 'pleasure' respectively. Philosophy from the ancient epoch was seen as "vision and existential choice of a way of life, a discourse and justification for chosen way of life, and articulation of the path or curriculum" that usually leads to the realization of the Ideals of the way of life. This choice was anchored on the Socratic dictum that an "unexamined life is not worth living". So, the focus of philosophy has been the transformation of one's way of life, one's mode of being in the world through self-reflection and rational deliberation (Hadot, 2002; Hadot and Davidson, 1995; and Snauwaert, 1993).

Following it existential choice, philosophy according to Snauwaert (2012), has a set of "discursive frameworks of understanding, methods of rational deliberation, and reflective exercises necessary for the transformation of one's being in accordance with the vision of existential choice" (78). It is from the chosen way of life of philosophy that schools were established to expose those attracted to its illuminative power to learn how to live that good life defined by philosophy. It is in the schools that proper definition of the way of life is given, and clear understandings and exercises that are necessary to live the good life defined by philosophy are developed, taught and experienced. It is the divergent of opinions as to what constitute this knowledge that generated or brought about different schools of philosophy and this consequently lead to different conception of education. Despite the differences discoverable in the various schools of philosophy and notions of education, there is a common thread which is that enduring happiness flows through conscious, rational self-reflection and discourse.

This perception of philosophy is closely linked with the understanding of democracy as a way of life, as ethical and political mode of being, which is found in the Platonic assertion that "man is a political animal "(Ekanem, 2013).

Philosophy is anchored on the presupposition that has been collaborated by cognitive science, which is that human being interpret and understand experience, including ideas, through frames of reference. Human beings think within the context of framework of discourse and understanding. As a discipline therefore, philosophy provides the articulation of competing frames of reference so as to enhance, nourish and enrich rational discourse. The issues that have to do with the normative questions raised before in this work occur within and is usually enriched by several ethical and political philosophical frameworks that provide meaning to discourses about them.

Democracy as either a concept or practice has a philosophical root and deontologically based upon liberty as self determination that stipulates a set of values and necessary for its sustainability.

Democracy can be viewed as a system of "rights that are premised upon the logic of equality" (Snauwaert, 2012). At the root of it is the firm belief in moral equality, which is a belief that all human beings possess an equal inherent dignity or worth. The basis of human dignity, upon which democracy is anchored, is captured in the principle of moral equality that is common to all contemporary political and ethical theories. Moral equality holds that every human being by virtue of their humanity possesses equal intrinsic value and dignity. Moral equality is not what is earned or bestowed on any person, rather it is inherent in our humanity. The logic of moral equality is graphically captured by Snauwaert (2012) thus:

\begin{abstract}
... if we are morally equal, then our "rights," our inviolable claims to the actual enjoyment of particular social goods, should be guaranteed by the society. The two basic rights that should follow from the egalitarian logic of democracy are: liberty and self- determination. If all human beings are equal, then they should have the right to define and pursue their own conception of the good life (consistent with the equal rights of others). They should have a right to decide their own interests, for there exists no higher moral authority. In addition, security of person should also be considered a basic right, for dignity and freedom cannot be fulfilled under the conditions of threat to the integrity of one's person. A right to self -determination follows...(79).
\end{abstract}

From this, it can be said that right to self-determination entails the fundamental notion of government by consent that have to do with political equality and concomitant rights like rights to freedom of expression, association, worship, own property, due process among others. Since all citizens are morally equals, the citizenry in a democracy have an inviolable right to determine their own interests and to have such interest represented directly or indirectly through a political process.

The values and principles outlined above provide us with a deep normative framework of democracy, but there are issues yet to be settled about their specification. This has generated several democratic, moral and political frameworks that hinge on the interpretation and implications of fundamental deep values and principles of democracy. Accordingly, there exists a range of democratic theories that have to do with the normative issues or questions. So, democratic philosophy has to do with certain theoretical frameworks that include value theory, political theory of authority, distributive 
theory, etc. All these help in the development of philosophies of democratic education when it comes to administration/management.

Also, philosophical frameworks allow for development and articulation of generative ideas (Hanson, 2007). The notion of "ideas" here is different from what may be termed as facts and information, and so are creative acts of meaning; constituting acts that make sense of individual experience. The implication of this is that ideas cannot be transmitted but rather emerge from an individual's reflection, which is distinctly unique according to their experience. Again, ideas have generative powers that enable them to move and transform us. Following this perspective therefore, philosophy cannot be said to be a production of theory per se, but instead "it is the pursuit of ideas- philosophy therefore speaks to how we live". This notion of philosophy assists in the illumination of the task of the democratic educator and citizen. From this point of view therefore there exists a plurality of educational ideas. Following this reasoning, it becomes imperative for educators to be involved with the a variety of philosophies as this will inspire and stimulate the generation of their own ideas, so the dynamics of their pedagogical practice follows the generation of these ideas (Ekanem, 2013).

\section{Rational Tools}

Philosophy has been able to develop a wide range of sophisticated methods of analysis. These methods include methods of and for argument, conceptual distinction, assessment and critique (Baggini and Fosl, 2003). These methods are founded in the rules of logic and logical analysis.

These according to Snauwaert (2012) include the following:

\subsection{Methods of Argument}

- Deduction

- Induction

- Validity and soundness

- Consistency (logical coherence)

- Refutation

- $\quad$ Dialectics etc (80)

\subsection{Methods for Assessment and Critique}

- Question begging

- Reductio ad absurdum

- $\quad$ Self -defeating arguments

- Regressions

- Sufficient reason

- Alternative explanations

- Ambiguity

- Excluded middle

- Bivalence

- Category errors

- Circularity

- Conceptual incoherence

- Counter examples

- False examples

- False dichotomy etc (80).

All these fall under error in reasoning, which is generally, refer to as fallacy.

\subsection{Methods for Conceptual Distinction}

- Apriori la posteriori

- Absolute/relative 
- Analytic/synthetic

- Necessary/contingent

- Essence/accident

- Necessary/sufficient

- Objective/subjective

- Think/thin concepts, etc (81).

These constitute the epistemological framework upon which human cognitive activities are analyzed and evaluated. The knowledge and application of these methods promote critical thinking, analysis, reflection and rational discourse and as such enhance the capacities of democratic educators and citizens.

\section{Conclusion}

Effort has been systematically made in this paper to show that education is a normative enterprise because it is driven by basic social values and as such becomes an imperative for social justice. These values and imperatives are fundamentally shaped through various dimensions of educational theories, policies and practices. These educational theories, policies and practices are products of deep reflections on education. It is these reflections that inspire specific values and principles that generate and create a way of life. It is also on the basis of these values and principles that democracy is understood as a political system that add ethical elements to the way of life. As individual that aspires to attain or achieve self-determination, the basic requirement towards this attainment is careful and rational reflection on social values. This indeed, provides the tonic for social justice and so become the imperative that inform the purposes and practices of education as it relates to administration/management. Philosophy it has been argued constitutes a mode of inquiry that uniquely enrich human capacity for rational reflection, and so it is vital for both democracy and the administration/management of education in any democratic society .Nigeria as an evolving democratic state there is therefore the need to sustain the values, principles and practices of a democratic culture through an educational framework that will aid to expose the learners to the wonderful activity of deep reflection, which only philosophy can provide.

\section{References}

Aristotle and Everson, S. The Politics, Cambridge Texts in the History of Political Thoughts. New York :Cambridge University Press, 1988.

Baggini, J. and Fosl, P.S. The Philosopher's Toolkit: A Compendium of Philosophical Concepts and Methods. Malden, M.A: Blackwell Publishers, 2003

Banner, J.M. and Cannon, H.G. The Elements of Teaching. New Haven: Yale University Press, 1997.

Carnoy, M. and Levin, H.M. Schooling and work in the Democratic State Stanford: Stanford University Press, 1985.

Counts, G.S. The Social Foundation of Education. New York :Scribner's Sons 1934.

Dahl, R. On Democracy. New Haven: Yale University Press, 2000

Ekanem and Ekefre E. N. "Education and religious intolerance in Nigeria: The Need for Essencism as a Philosophy" Journal of Educational and Social Research Vol. 3, No 2, May 2013, Pp $303-310$.

Ekanem, S.A. "Science and Human Nature: A Complex Dynamics of reality" Mediterranean Journal of Social sciences, Vol.4, No 2, May 2013, Pp. 389 400.

Ekanem, S. A." The Platonic Prophesy and the Crisis of Leadership and Political Instability in Africa: The Nigerian Dilemma" A Paper Presented at the19th Annual International Conference of The International Society of African Philosophy and Studies(ISAPS) Held at Nnamdi Azikiwe University from $27^{\text {th }}$ $-2 g^{\text {th }}$ May, 2013.

Feingberg, W. Common Schools/Uncommon Identities: National Unity and Cultural Difference. New Haven: Yale University Press, 1998.

Foucault, M. The Hermeneutics of Subject, Lecturers at the College De France 1981 - 82 Translated by Arnold I. David son Edited by Frederic Gross New York: Picader, 2005.

Freire, P. Pedagogy of Freedom: Ethics, Democracy and Civic Courage, Critical Perspective Series. Lanham: Rowman \& Littlefield Publishers, 1998.

Gutmann, A. Democratic Education. Revised Edition Princeton: Princeton University Press, 1999.

Hadot, P. What is Ancient Philosophy? Cambridge: Harvard University Press, 2002.

Hadot, P. and Davidson, A. I. Philosophy as a Way of Life: Spiritual Exercises from Socrates to Foucault. New York: Blackwell, 1995.

Hansen, D, Ethical Visions of Education: Philosophies in Practice. New York: Teachers College Press, 2007.

Karier, C. J. The Individual Society and Education. Urbana: The University of Illinois Press, 1986.

Lakoff, G. Moral Politics: How Liberal and Conservatives Think. $2^{\text {nd }}$ ed. Chicago: University of Chicago Press, 2002.

Macpherson, C. B. Democratic Theory: Essays in Retrieval. Oxford: University Press. 1973.

Rawl, J. A. Theory of Justice. Cambridge: Belknap Press of Harvard University Press, 1971.

Snauwaert, D.T. Democracy, Education and Governance: A Developmental Conception. Albany, New York: The state University of New York Press, 1993.

Snauwaert, D.T. "The importance of philosophy for education in Democratic society" INFACTIS PAX Journal of Peace Education and Social Justice, Vol. 6 Number 2, 2012, Pp. $73-84$. 